\title{
School vision screening programmes in reducing uncorrected refractive error among children in Low and Middle-Income countries-LMIC (systematic review)
}

\begin{abstract}
Background: The prevalence of uncorrected refractive error among schoolage children is on the rise with detrimental effect on academic performance and socio-economic status of those affected. School vision screening programmes appear to be an effective way of identifying children with uncorrected refractive errors so early intervention can be made. Despite the increasing popularity of school vision screening programmes over the past few years, there is a lot of debate on its effectiveness in reducing the proportion of children with uncorrected refractive error in the long term, especially in settings where resources are limited. Some studies argue that school vision screening programmes are effective while other studies have reported otherwise. The purpose of this systematic review was to assess the effectiveness of school vision screening programmes in reducing uncorrected refractive error among children in low and middle income countries using evidence from published studies.
\end{abstract}

Methods and findings: A comprehensive and systematic strategy was used to search various databases including PubMed, Cochrane Central Register of Controlled Trials (CENTRAL) which contains the Cochrane Eyes and vision Trial Register, the Cochrane Library, Medline (1980-2018), CINAHL, Academic Search Premier, Web of Science, the WHO's Library Information System, Africa-Wide and Scopus. The search was restricted to articles published in English. Randomized control trials, cross-sectional studies, case-control studies and cohort studies were included in this review. Participants included school children with refractive error. Full-text review of search results, data extraction and risk of bias assessment was done by two independent reviewers. The certainty of the evidence was assessed using the GRADE approach and data were pooled using the random-effect model. Thirty studies met the inclusion criteria. This review found moderate certainty evidence indicating that school vision screenings may be effective in reducing uncorrected refractive error among school children by $81 \%$ (95\% CI: $77 \%$; $84 \%), 24 \%$ (95\% CI: $13 \% ; 35 \%$ ) and $20 \%$ (95\% CI: $18 \% ; 22 \%$ ) at two, six, and more than six months respectively after its introduction.

Results: Results of this review also suggest that school vision screening may be effective in achieving 54\% (95\% CI: $25 \% ; 100 \%), 57 \%$ (95\% CI: $46 \%$; $70 \%$ ), $37 \%$ (95\% CI: $26 \%$; $52 \%$ ), and $32 \%$ (95\% CI: $14 \%$; $72 \%$ ) spectaclewear compliance among school children at less than three months, at three
Volume 10 Issue 4 - 2020

\author{
Abraham Opare, ${ }^{1,2}$ Leila H Abdullahi' ${ }^{1,3}$ Deon \\ Minnies, ${ }^{1,2}$ Colin Cook, ${ }^{1,2}$ Maylene Shung- \\ King, ${ }^{1,4}$ Grace Mwangi ${ }^{1,2}$ \\ 'School of Public Health and Family Medicine, University of \\ Cape Town, South Africa \\ ${ }^{2}$ Community Eye Health Institute-University of Cape Town, \\ South Africa \\ ${ }^{3}$ Institute of Infectious Disease \& Molecular Medicine, University \\ of Cape Town, South Africa \\ ${ }^{4}$ Division of Health Policy \& Systems, University of Cape Town, \\ South Africa
}

Correspondence: Abraham Opare, School of Public Health and Family Medicine, University of Cape Town, South Africa, Email oprabrol@myuct.ac.za

Received: March 30, 2020| Published: August 31, 2020

months, at six months and at more than six months respectively after its introduction (low to moderate certainty evidence). This review further found moderate to high certainty evidence indicating that school vision screening, together with provision of spectacles, may be relatively cost effective, safe and has a positive impact on the academic performance of school children.

Conclusion: The findings of this review show that school vision screening, together with provision of spectacles, may be a safe and cost-effective way of reducing the proportion of children with uncorrected refractive error, with long-term positive impact on academic performance of children. Most of the studies included in this review were, however, conducted in Asia. Research to investigate the effectiveness of school vision screening programmes in other parts of the world like Africa where few studies have been conducted is highly recommended.

Keywords: school vision screening programmes, visual impairment, refractive error, case-control studies

\section{Introduction}

Refractive error is the most common cause of visual impairment especially among children according to recent studies and the World Health Organization (WHO) report. ${ }^{1}$ Globally, it is estimated that $43 \%$ of visual impairment is due to uncorrected refractive error. ${ }^{2}$ Refractive error is an intrinsic optical defect of the eye in which parallel rays of light coming from optical infinity are focused either in front or behind the retina with accommodation fully relaxed. ${ }^{3}$ Without timely treatment, refractive errors, due to the poor image they present to the retina, can lead to more serious eye conditions like amblyopia. ${ }^{4}$ Over the years, school vision screening programmes have been used in different countries and settings to detect refractive errors, especially during the critical period of visual development where early treatment can prevent more complicated conditions like amblyopia. ${ }^{4}$ Most school vision screening programmes are however concentrated in developed countries where they are mostly provided as part of the healthcare system by the government or incorporated into the formal education system. ${ }^{5}$ In low and middle- income countries (LMICs) however, the situation is different. Despite recommendations from the WHO advocate to incorporate vision screening programmes into the health care system of these countries as part of it Vision 2020 
initiative, lack of government commitment, inadequate infrastructure, funding and a limited number of health care professionals continue to be a major hindrance. ${ }^{6,7}$ The lack of government's commitment and support for the introduction of vision screening programmes in most LMICs have mainly been attributed to the lack of evidence to support the effectiveness of these programmes in areas where they have already been introduced. ${ }^{4,5}$ Few studies that have sought to assess the effectiveness of these programmes have mainly focused on vision screening programmes in developed countries.

In January 2018, a revised Cochrane review examined vision screening for correctable visual deficit due to refractive error in school-age children and adolescents. ${ }^{8}$ In their conclusion, the authors acknowledged that despite evidence from China (where five out of the seven studies included in their review were conducted) suggesting that vision screening may be effective in improving spectacle wearing and educational outcome, the applicability of these findings to other parts of the world where few or none of the studies that met their inclusion criteria were conducted was not clear. ${ }^{8}$ A recommendation for more studies to be conducted in these areas was made. The Cochrane review, however, included only RCTs making other non-RCTs that possibly provide the best opportunity at present to evaluate the effectiveness of the programmes in these areas' ineligible for inclusion. Considering the fact that only a few RCTs have assessed school vision screening in LMICs, it has become necessary for a review that examines all the available evidence at present to be conducted. This review included both RCTs and non-RCTs evaluating the effectiveness of the programmes in the LMICs context.

\section{Methods}

Reporting of the finding of this systematic review was guided by the Preferred Reporting Items for Systematic Reviews and Meta-Analyses (PRISMA) guidelines. This review was registered prospectively in PROSPERO with registration number CRD42018089631.

\section{Types of studies}

We included the following study design type in this review; RCTs, cross-sectional studies, case-control studies, and cohort studies.

\section{Participants}

We included children who had undergone vision screening as part of school vision screening programmes in the LMICs setting and found to have refractive error. Participants with other ocular pathologies accounting for poor vision were excluded from this systematic review.

\section{Types of outcome measure}

Primary outcome: The proportion of children with uncorrected or sub-optimally corrected refractive error.

Secondary outcomes: Effect of school screening programmes on the academic performance of children.

Adverse effect of school vision screening programmes (i.e. anxiety from interviews, misdiagnosis, symptoms associated with the use of prescribed spectacles, etc.). Cost-effectiveness of school vision screening programmes. Influence of school vision screening programmes on compliance with spectacle wearing.

\section{Search methods}

\section{Identification of studies}

To identify studies suitable for this systematic review, a comprehensive and systematic search strategy was used. A search of eligible articles was performed using keywords, truncated terms, the Boolean operator and Medical Subject Heading (MESH) terms. The search was restricted to articles published between 1980 and 2018 and the search was done from January to August 2018. The following electronic databases were searched; PubMed, Cochrane Central Register of Controlled Trials (CENTRAL) which contains the Cochrane Eyes and vision Trial Register, the Cochrane Library, Medline (1980-2018), CINAHL, Academic Search Premier, Web of Science, the WHO's Library Information System, Africa-Wide and Scopus. Combined search of MESH terms, titles and abstracts were used for each step of the search. The search was restricted only to articles written in English. Studies involving vision screening programmes that targeted subgroup population such as children with specific ocular pathologies other than refractive error (e.g. congenital glaucoma, congenital cataract, etc.) were excluded. Filters were also used during the search for articles to ensure that only studies in LMICs were included in this systematic review. Countries names and regional names were used in the electronic search. This was to ensure that both country-specific records and records indexed by a regional term such as 'West Africa' were included in this systematic review. In instances where a country has English and a local name, both names were used to increase the sensitivity of the electronic search in identifying all the relevant articles for the review. Efforts were made to identify unpublished studies, government reports, theses, dissertation and conference papers by searching google (including google scholar) and WorldCat. Additionally, the reference list of all the included studies were searched for any articles that may have been missed during the initial search. A detailed description of the search strategy used in this review is included in appendix 5 .

\section{Data collection and analysis}

\section{Selection of studies}

Selection of studies to be included in this systematic review went through three phases involving two independent reviewers. In the first phase, two reviewers; Abraham Opare (AO) and Leila Abdullahi (LA) checked the electronic search results and selected all studies that made reference to refractive error, myopia, hyperopia, astigmatism, and vision screening. Any identified article that was found to be clearly irrelevant at first glance was excluded. In the second phase of the selection process, the two independent reviewers (AO and LA) screened the titles and abstracts of studies identified to be relevant in the first phase to determine their eligibility for inclusion in the systematic review. The full text was obtained by AO for studies that had no abstract. In the third and final phase of the selection process, the two reviewers (AO and LA) performed a full-text review of all articles whose abstracts were found to be relevant in the second phase. The full-text review was also done for articles whose abstract failed to provide a clear description of the study. Using the study's inclusion and exclusion criteria, the two reviewers (AO and LA) finally selected the studies to be included in the systematic review. In instances where we were unable to come to an agreement on whether a paper was eligible for inclusion, an arbitrator Colin Cook (CC) who is an expert in the field was consulted. The search and selection of articles for this systematic review were summarized using the PRISMA flow chart. The characteristics of all included studies in this review and the reason for exclusion of studies have been well documented using tables.

\section{Data extraction and management}

Data from the selected studies were extracted using a standardized Cochrane collaboration data extraction form that was modified to suit this systematic review. Initial piloting of the data extraction form 
was done to ensure uniformity among the two independent reviewers (AO and LA). Where possible, we extracted information on study participants including their age, sex, school grade and number of participants, study setting (city and country), additional intervention (spectacle provision, health education, teacher incentive etc.) and type of outcome measure (spectacle compliance, cost of screening, improvement in academic performance etc.). Indicators of the severity of refractive error such as the visual acuity in the worse eye were also extracted. Additionally, any data deemed to be an appropriate indicator of the effectiveness of a school vision screening program such as the number of children who benefited from spectacle correction of their refractive error, compliance with wearing of spectacles provided as part of vision screenings, etc. was also extracted.

\section{Assessment of risk of bias in included studies}

Assessment of risk of bias for prevalence studies was done using the Hoy criteria tool. A 10-point scale was applied to all the crosssectional studies to assess both their internal and external validity. A score of 8 or more "yes" in the 10-point scale was considered a low risk of bias, 6-7 score, moderate risk of bias and 5 or less "yes" high risk of bias. For RCTs, the risk of bias was assessed using the Cochrane Effective Practice and Organization of Care (EPOC) tool. For each study, we independently reported our judgment of the risk of bias as either being low, high or unclear and cases of disagreements were resolved by an arbitrator (CC) who is an expert in the field. Where deemed necessary, a funnel plot was used to check for publication bias across the included studies.

\section{Subgroup analysis}

When and where appropriate, subgroup analysis was done to determine the effect of the definition used as an indication of spectacle compliance in the various studies on the pooled spectacle compliance the measure of the intervention effect. We expressed the result of each study which assessed our primary outcome as a risk difference with the corresponding 95\% confidence interval (CI). Compliance with spectacle-wearing was expressed as proportions with the corresponding $95 \% \mathrm{CI}$. We grouped studies based on the follow-up period, study design and definition used as an indication of spectacle compliance to get reasonable results for an overall estimate of effect.

\section{Dealing with missing data}

We did not have cases of missing data in this systematic review and therefore made no contact with primary study authors for missing data.

\section{Heterogeneity assessment}

Studies included in this systematic review were checked for heterogeneity by examining their characteristics (study design, population, setting, etc.) and risk of bias. The Cochran's Q-test and the Higgins Chi-square test for heterogeneity was used to statistically explore any heterogeneity among the included studies using an alpha level of $10 \%$. Heterogeneity was considered as significant if the Chisquare was above $50 \%$ and this was taken into consideration in the grading of evidence.

\section{Data synthesis and analysis}

Analysis of quantitative data was done using RevMan 5.3 software. Data from studies with a low or medium risk of bias found to be relatively similar in terms of outcome, follow-up period and participants were pooled together in a meta-analysis using the random-effect model. The measure of effect used as an estimate for the reduction in the proportion of children with uncorrected refractive error after the introduction of school vision screening was risk difference. This was calculated by subtracting the proportion of children with uncorrected refractive error prior to exposure to school vision screening from the proportion of children with uncorrected refractive error post-exposure to school vision screening. In all instances, the $95 \%$ CI was presented. Additionally, the STATA 14 statistical package was used to obtain estimates of the proportion of children with uncorrected refractive error where necessary. In cases where statistical analysis of data was not possible, a narrative technique was employed in presenting the result. A subgroup analysis was done where deemed necessary to examine the impact of the definition used as an indication of compliance with spectacle-wear on the size and direction of the effect.

\section{Quality of evidence}

The quality of the evidence presented in this systematic review was assessed using the GRADE approach. Based on the level of confidence we have in the outcome, we graded the evidence as either low moderate or high certainty evidence. We judged the effect estimate in this review as high certainty evidence if we were very confident the true effect lies close to that of the estimated effect. Estimates were judged as moderate certainty evidence if we were moderately confident that the true effect lies close to that of the estimate of effect. In instances where had very little confidence that the true effect lies close to the effect estimate, that estimate was judged as low certainty evidence. ${ }^{9}$

\section{Results}

\section{Search results}

Our electronic search identified 2101 articles. After removal of duplicates, 1583 articles remained for screening. 1532 articles which were found to be irrelevant to this review were excluded leaving 51 articles for full-text review. Using the predefined inclusion and exclusion criteria as a guide, 18 articles were excluded based on reasons given in Table 1, and full text for 3 articles could not be obtained. Thirty (30) articles which met the inclusion criteria were included in this review. The processes involved in the search, screening, and selection of articles for inclusion in this review is summarized using the PRISMA flow diagram (Figure 1).

\section{Description of included studies}

Thirty articles retrieved from the electronic search met our inclusion criteria. Out of these, six were cluster RCTs with schools as clusters, ${ }^{9-15}$ four were RCTs with randomization done at the individual level. ${ }^{16-19}$ three were non-RCTs, ${ }^{20-22}$ six were cohort studies ${ }^{23-28}$ and eleven were cross-sectional studies..$^{29-39}$ Twelve of the eligible studies were conducted in India. ${ }^{23,33-34,37,38,40-47}$ eight were conducted in China. ${ }^{48-53}$ One study was conducted in Chile, one in Tanzania, one was conducted in South Africa, one was from Mexico, one was conducted in Oman, one was conducted in Nepal, one was done in Thailand and one was conducted in Botswana. All the included studies enrolled both males and females children. A detailed description of all included studies is provided in the Table 2 .

\section{Characteristics of excluded studies}

Eighteen studies which did not meet the pre-defined inclusion criteria were excluded from this review. Table 3 gives a detailed description of the excluded studies and the reasons for their exclusion. 
Table I Characteristics of Included studies

\begin{tabular}{|c|c|c|c|c|c|}
\hline Study ID & Study design & $\begin{array}{l}\text { Population /setting (location and } \\
\text { social context) }\end{array}$ & $\begin{array}{l}\text { Total no. } \\
\text { enrolled }\end{array}$ & $\begin{array}{l}\text { Sex/age } \\
\text { (years) }\end{array}$ & $\begin{array}{l}\text { Duration of } \\
\text { participation }\end{array}$ \\
\hline Wedner, 2008 & Cluster randomized trial & $\begin{array}{l}\text { School children were drawn from } 37 \\
\text { senior secondary schools in Dar es } \\
\text { Salaam }\end{array}$ & 6904 & $\begin{array}{l}\text { Male and } \\
\text { female, aged } \\
\text { I I- } 25 \text { years }\end{array}$ & 6-month period \\
\hline Ma, 2014 & Cluster randomized trial & $\begin{array}{l}\text { Primary school children in fourth and } \\
\text { fifth grades in Western China }\end{array}$ & 3177 & $\begin{array}{l}\text { Male and } \\
\text { female, mean } \\
\text { age } 10.5 \text { years }\end{array}$ & 8-month period \\
\hline Ma, 2015 & Cluster randomized trial & $\begin{array}{l}\text { Primary school children in fourth and } \\
\text { fifth grades in Western China }\end{array}$ & 3177 & $\begin{array}{l}\text { Male and } \\
\text { female, mean } \\
\text { age 10.5years }\end{array}$ & 8-month period \\
\hline Yi, 2015 & Cluster randomized trial & $\begin{array}{l}\text { School in schools at Shanghai and } \\
\text { Suzhou/Wuxi in China }\end{array}$ & 4376 & $\begin{array}{l}\text { Male and } \\
\text { female, aged } \\
10-12 \text { years }\end{array}$ & 6-month period \\
\hline $\begin{array}{l}\text { Morjaria, } \\
2017\end{array}$ & $\begin{array}{l}\text { Non-inferiority, double- } \\
\text { masked, Randomized } \\
\text { clinical trial }\end{array}$ & $\begin{array}{l}\text { School children in government } \\
\text { secondary schools in urban and peri- } \\
\text { urban areas surrounding Bangalore in } \\
\text { Karnataka State in India }\end{array}$ & 23345 & $\begin{array}{l}\text { Male and } \\
\text { female, aged } \\
\text { II-I5 years }\end{array}$ & 3-4-month period \\
\hline $\begin{array}{l}\text { Congdon, } \\
2011\end{array}$ & $\begin{array}{l}\text { A randomized, controlled } \\
\text { trial. }\end{array}$ & $\begin{array}{l}\text { School children in years I and } 2 \text { of all } 20 \\
\text { junior and senior high schools in 3, rural } \\
\text { townships in Guangdong, China }\end{array}$ & 11423 & $\begin{array}{l}\text { Male and } \\
\text { female, aged } \\
12-17 \text { years }\end{array}$ & 6-month period \\
\hline Zeng, 2009 & $\begin{array}{l}\text { Randomized, double-blind, } \\
\text { Clinical trial. }\end{array}$ & $\begin{array}{l}\text { Junior high school students from urban } \\
\text { Guangzhou, China }\end{array}$ & 4607 & $\begin{array}{l}\text { Male and } \\
\text { female, aged } \\
12-15 \text { years }\end{array}$ & I-month period \\
\hline Zhou, 2017 & $\begin{array}{l}\text { a randomized, double- } \\
\text { masked non-inferiority trial }\end{array}$ & $\begin{array}{l}\text { School children in grades } 7 \text { and } 8 \text { (in nine } \\
\text { Chinese secondary schools }\end{array}$ & 9889 & $\begin{array}{l}\text { Male and } \\
\text { female, aged } \\
12-15 \text { years }\end{array}$ & 2 Month period \\
\hline Wang, 2017 & $\begin{array}{l}\text { cluster randomized, } \\
\text { investigator-masked, } \\
\text { controlled trial }\end{array}$ & $\begin{array}{l}\text { School children from primary schools in } \\
9 \text { counties in Guangdong and Yunnan } \\
\text { provinces, China }\end{array}$ & 10,234 & $\begin{array}{l}\text { Male and } \\
\text { female, aged } \\
9-12 \text { years }\end{array}$ & 6-month period \\
\hline & descriptive study & $\begin{array}{l}\text { Qassim Province who has been } \\
\text { prescribed the spectacles during } \\
\text { the school year } 2010-201 \mathrm{I} \text {. }\end{array}$ & & aged $7-13$ years & \\
\hline Limburg, I 995 & $\begin{array}{l}\text { cross-sectional } \\
\text { descriptive study }\end{array}$ & $\begin{array}{l}\text { Middle school children in New Delhi, } \\
\text { India }\end{array}$ & 46672 & $\begin{array}{l}\text { Male and female, } \\
\text { aged } 10-15 \text { years }\end{array}$ & N/A \\
\hline Sumana, 2015 & $\begin{array}{l}\text { cross-sectional } \\
\text { descriptive study }\end{array}$ & $\begin{array}{l}\text { School going children in Salagame, } \\
\text { Hassan in India }\end{array}$ & 391 & $\begin{array}{l}\text { Male and female, } \\
\text { aged } 9-16 \text { years }\end{array}$ & 6-month period \\
\hline Rustagi,20।2 & $\begin{array}{l}\text { intervention } \\
\text { study }\end{array}$ & $\begin{array}{l}\text { middle and secondary government } \\
\text { schools' children } \\
\text { in the northwest district of Delhi }\end{array}$ & 1123 & $\begin{array}{l}\text { Male and female, } \\
\text { aged II-I8 } \\
\text { years, mean age } \\
14.25\end{array}$ & 8-month period \\
\hline Limburg, 1999 & $\begin{array}{l}\text { Retrospect } \\
\text { ive Cohort } \\
\text { study }\end{array}$ & $\begin{array}{l}\text { primary and middle schools' } \\
\text { children from } 6 \mathrm{I} \text { districts in } \\
\text { India }\end{array}$ & $\begin{array}{l}5.39 \\
\text { million }\end{array}$ & $\begin{array}{l}\text { Male and female, } \\
\text { aged 6-15 years }\end{array}$ & $\begin{array}{l}\text { 60-month period } \\
(5 y r s)\end{array}$ \\
\hline Khandekar, 2008 & $\begin{array}{l}\text { cross- } \\
\text { sectional } \\
\text { descriptive } \\
\text { study }\end{array}$ & $\begin{array}{l}\text { School children in } 2 \text { regions in } \\
\text { Central India }\end{array}$ & 77 & $\begin{array}{l}\text { Male and female, } \\
\text { age not reported }\end{array}$ & $\begin{array}{l}3 \text { to 4-month } \\
\text { period }\end{array}$ \\
\hline
\end{tabular}




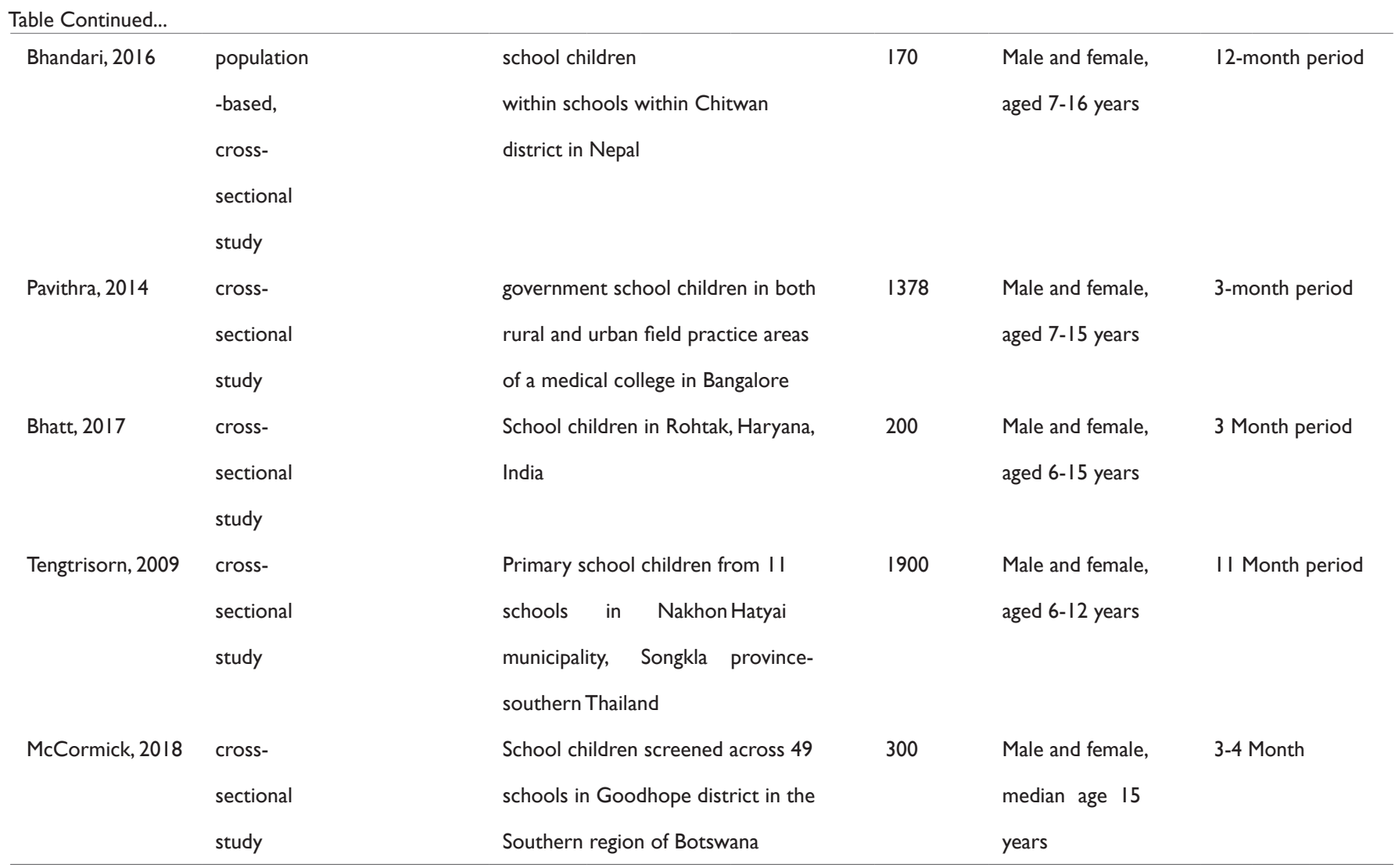

Table 2 Characteristics of excluded studies

\begin{tabular}{|c|c|}
\hline Author, Year & Reason for exclusion \\
\hline Odedra, 2008 & Not the outcome of interest \\
\hline Rono, 2018 & Not the outcome of interest \\
\hline Noma, 2012 & Not the outcome of interest \\
\hline Sudhan, 2012 & Not the outcome of interest \\
\hline Zhang, 2009 & Not the outcome of interest \\
\hline Khandekar, 2009 & Not the outcome of interest \\
\hline Chang, 2017 & Not the outcome of interest \\
\hline Kaur, 2016 & Not the outcome of interest \\
\hline Diao, 2016 & Not the outcome of interest \\
\hline Ondrejkova, 2013 & Not the outcome of interest \\
\hline Arif, 2014 & Not the outcome of interest \\
\hline Ajuwon, 1996 & Not the outcome of interest \\
\hline Esteso, 2007 & Not the outcome of interest \\
\hline Santos, 20II & Non-English publication \\
\hline \multirow[t]{2}{*}{ Frick, 2009} & $\begin{array}{l}\text { Cost-effectiveness assessed using a hypothetical school } \\
\text { vision screening program }\end{array}$ \\
\hline & (modeling) rather than through a primary study. \\
\hline Frick, 2009 & $\begin{array}{l}\text { Cost-effectiveness assessed using a hypothetical school } \\
\text { vision screening program }\end{array}$ \\
\hline
\end{tabular}


Table 3 Risk of Bias Assessment for Randomized and Non-Randomized control trial

\begin{tabular}{|c|c|c|c|c|c|c|c|c|}
\hline Study ID & $\begin{array}{l}\text { Random } \\
\text { sequence } \\
\text { generation } \\
\text { (selection } \\
\text { bias) }\end{array}$ & $\begin{array}{l}\text { Allocation } \\
\text { concealment } \\
\text { (selection } \\
\text { bias) }\end{array}$ & $\begin{array}{l}\text { Blinding } \\
\text { participants } \\
\text { and personnel } \\
\text { (performance } \\
\text { Bias) }\end{array}$ & $\begin{array}{l}\text { Blinding } \\
\text { outcome } \\
\text { assessment } \\
\text { (detection } \\
\text { bias) }\end{array}$ & $\begin{array}{l}\text { Incomplete } \\
\text { outcome } \\
\text { data } \\
\text { (attrition } \\
\text { bias) }\end{array}$ & $\begin{array}{l}\text { Selective } \\
\text { reporting } \\
\text { (Reporting Bias) }\end{array}$ & $\begin{array}{l}\text { Baseline } \\
\text { imbalance } \\
\text { (cluster } \\
\text { RCTs only) }\end{array}$ & $\begin{array}{l}\text { Are the } \\
\text { study } \\
\text { results } \\
\text { valid? }\end{array}$ \\
\hline $\begin{array}{l}\text { Wedner } \\
2008\end{array}$ & Low & Low & Low & Unclear & Low & Low & Unclear & Yes \\
\hline $\mathrm{Ma}, 2014$ & Low & Low & Low & Low & Low & Unclear & Low & Yes \\
\hline Ma, 2015 & Low & Low & Low & Low & Low & Unclear & Low & Yes \\
\hline Yi, 2015 & Low & Low & Low & Low & Low & Unclear & Unclear & Yes \\
\hline $\begin{array}{l}\text { Morjaria, } \\
2017\end{array}$ & Low & Low & Low & Low & Low & Low & N/A & Yes \\
\hline $\mathrm{Ma}, 2018$ & Unclear & Low & Low & Unclear & Low & Low & & \\
\hline Kaey, 2010 & N/A & Low & Low & Low & Low & $\begin{array}{l}\text { High (Some planned } \\
\text { results to be } \\
\text { reported from the } \\
\text { registration of the } \\
\text { trial not reported) } \\
\text { some of the missing } \\
\text { outcomes will have } \\
\text { been of relevance } \\
\text { to this review e.g. } \\
\text { at } 6-12 \text { months } \\
\text { after dispensing } \\
\text { andspectacle use } \\
\text { cost-effectiveness }\end{array}$ & & \\
\hline $\begin{array}{l}\text { Congdon, } \\
2011\end{array}$ & Low & Low & Unclear & Unclear & Low & $\begin{array}{l}\text { High (Some planned } \\
\text { results to be } \\
\text { reported from the } \\
\text { registration of the } \\
\text { trial not reported) }\end{array}$ & N/A & Yes \\
\hline Zeng,2009 & Low & Low & Low & Low & Low & $\begin{array}{l}\text { High (Some planned } \\
\text { results to be } \\
\text { reported from the } \\
\text { registration of the } \\
\text { trial not reported) } \\
\text { some of the } \\
\text { missing. outcomes } \\
\text { will have been of } \\
\text { relevance to this } \\
\text { review e.g. continued } \\
\text { spectacle use at } \\
6-12 \text { months after } \\
\text { dispensing and cost- } \\
\text { effectiveness }\end{array}$ & N/A & Yes \\
\hline $\begin{array}{l}\text { Zhou, } \\
2017\end{array}$ & Low & Low & Low & Low & Low & Low & N/A & Yes \\
\hline $\begin{array}{l}\text { Wang, } \\
2017\end{array}$ & Unclear & Low & Low & Low & Low & Low & Unclear & Yes \\
\hline $\begin{array}{l}\text { Narayanan, } \\
2018\end{array}$ & N/A & Unclear & Unclear & Low & Low & Low & & \\
\hline Priya, 20I4 & N/A & Unclear & Low & Unclear & Low & Low & & \\
\hline
\end{tabular}




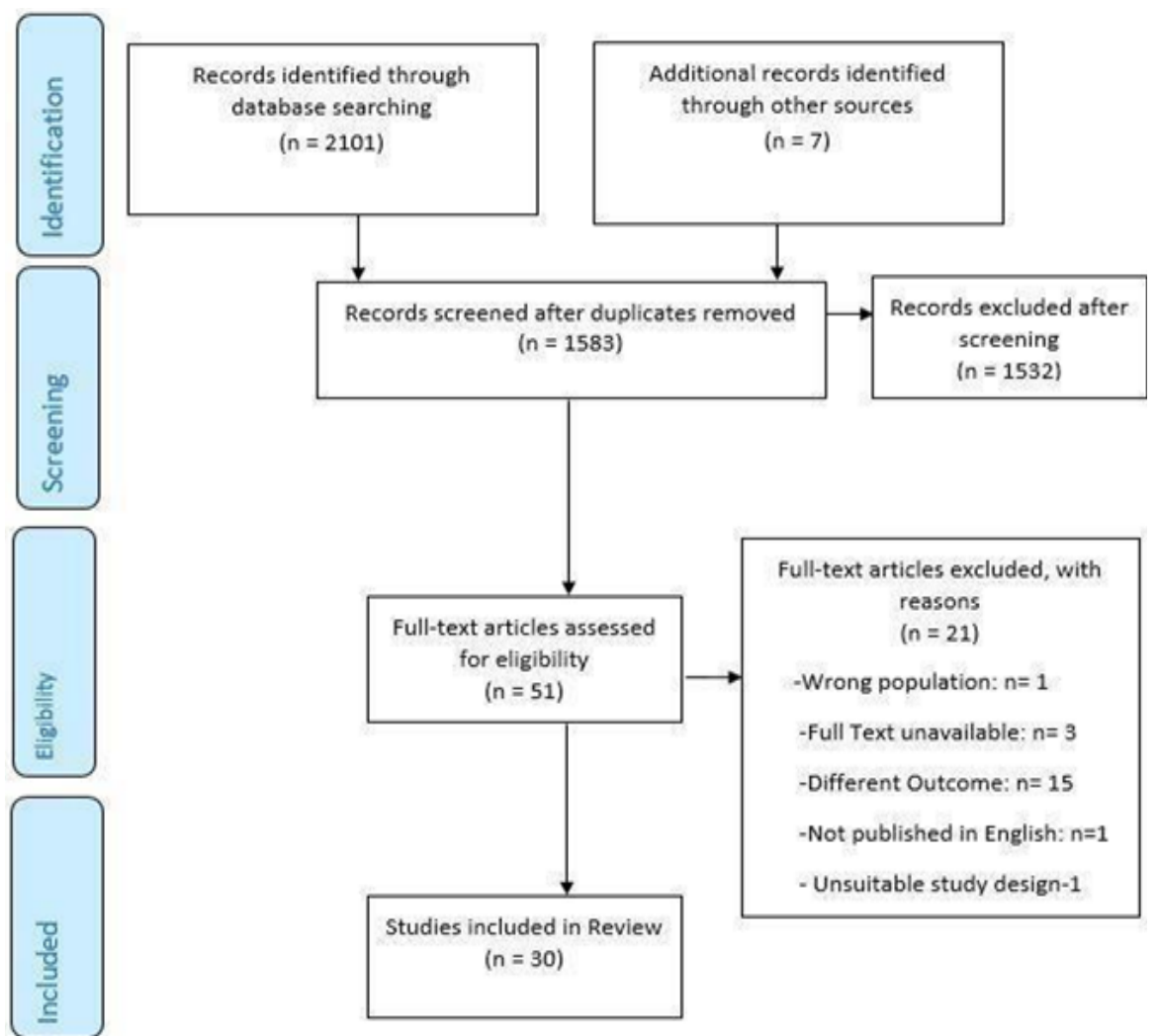

Figure I PRISMA flow diagram.

\section{Risk of bias assessment (RCTs and non-RCTs)}

Risk of bias for RCTs and non-RCTs were assessed using the Cochrane Effective Practice and Organization of Care (EPOC) tool. A summary of the risk of bias assessment for RCTs and non-RCTs is shown in Figure 2.

\section{Risk of bias assessment (prevalence studies)}

Risk of bias assessment for prevalence studies was done using the Hoy risk of bias assessment tool which was modified to suit this systematic review. Table 1 summarizes the risk of bias assessment for all the prevalence studies.

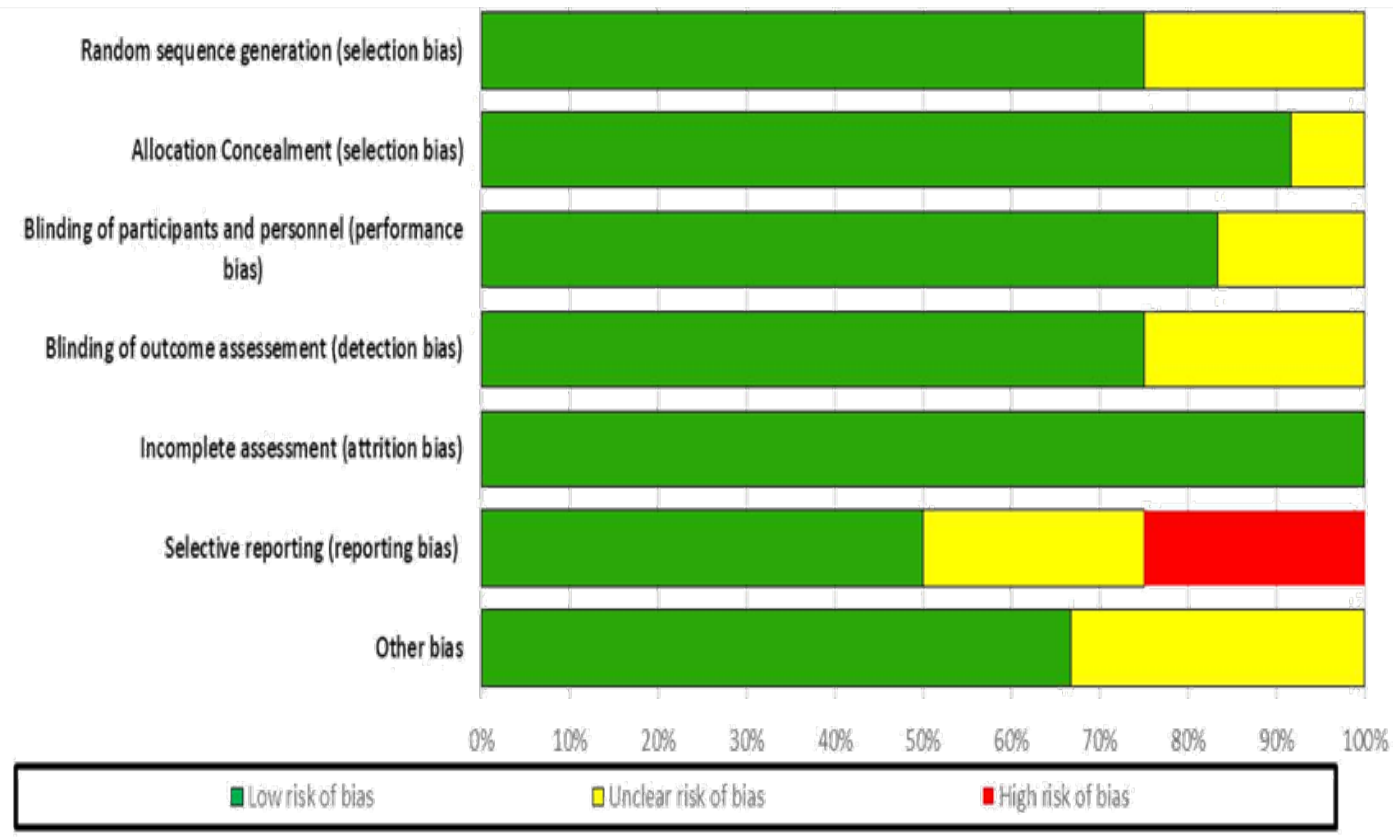

Figure 2 Risk of bias assessment for randomized and non-randomized control trial. 


\section{Risk of bias assessment (cohort studies)}

Risk of bias assessment for cohort studies was done using a risk of bias assessment tool for cohort studies developed by Cochrane. Table 2 summarizes the risk of bias assessment for all the cohort studies included in this systematic review.

\section{Quantitative data synthesis}

Outcome: Effectiveness of school vision screening programmes in reducing uncorrected refractive error among children.

\section{Two months post-school vision screening}

One study (19) suggests that school vision screening may be effective in reducing the proportion of children with an uncorrected refractive error by $81 \%(95 \%$ CI: $77 \% ; 84 \%)$, two months after its introduction (Figure 3). This was judged to be moderate certainty evidence, downgraded one level for indirectness as this effect estimate might only be specific to China where the study was conducted.

\section{Six months post-school vision screening}

Five studies $(13-15,61,62)$ assessed the reduction in the proportion of children with an uncorrected refractive error at 6 months after school vision screening. These studies show that school vision screening programmes may be effective in reducing the proportion of children with an uncorrected refractive error by $24 \%$ (95\% CI: $13 \%$; $35 \%$ ). We judged this to be moderate certainty evidence, downgrading one level for inconsistency.

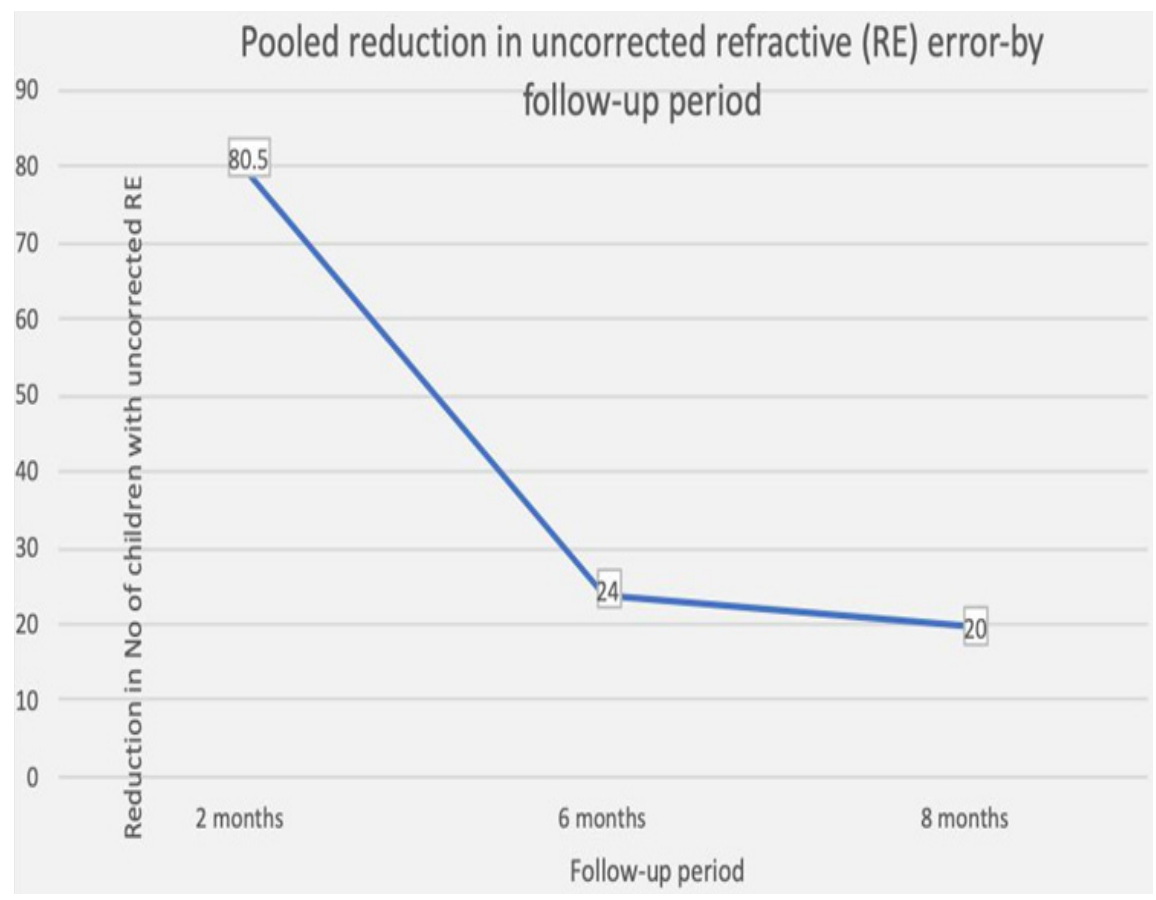

Figure 3 Pooled reductions in uncorrected refractive error by follow-up period.

\section{Eight months post-school vision screening}

This was assessed by one study. ${ }^{11}$ This study shows that school vision screening programmes may be effective in reducing the proportion of children with an uncorrected refractive error by $20 \%$ (95\% CI: $18 \% ; 22 \%)$, (Figure 4$)$ at 8 months after its introduction. We judged this to be moderate certainty evidence, downgrading one level for indirectness since the effect estimate may be specific to China where the study was conducted.

Figure 5 shows pooled reduction in proportion of children with uncorrected refractive error by follow-up period.

Outcome: School vision screening and compliance with spectacle wear less than three months after school vision screening compliance with spectacle wear at less than 3 months after school vision screening was assessed by three studies, ${ }^{19,20-28}$ These studies show that $54 \%$ of children provided with spectacles as part of school vision screenings may be compliant with it wear at less than 3-month follow-up (95\%
CI: $27 \% ; 100 \%, \mathrm{I} 2=100 \%$ ) (Figure 6). We judged this to be moderate certainty evidence downgrading 1 level for inconsistency.

\section{Three months after school vision screening}

Six studies $(17,31,60,61,63,64)$ assessed spectacle compliance at 3 months after school vision screening. These studies indicate that $57 \%$ of children provided with spectacles as part of school vision screening programmes may be compliant with it wear at three-month follow- up (95\% CI: 47\%; 70\%, I2=94\%) (Figure 7). We judged this evidence to be of low certainty, downgrading 2 levels for high risk of bias and inconsistency.

\section{Six months after school vision screening}

This was reported by nine studies. These studies revealed that $37 \%$ of children provided with spectacles as part of school vision screening may be compliant with it wear at six-month follow-up (95\% CI: $26 \%$; $52 \%$, I2 $=94 \%$ ], moderate certainty evidence (downgraded one level for inconsistency) (Figure 6). 


\begin{tabular}{|c|c|c|c|c|c|c|c|c|}
\hline \multirow{2}{*}{$\frac{\text { Study or Subgroup }}{2.4 .1 \text { Self-Reported }}$} & log[Spectacle compliance] & \multirow[t]{2}{*}{ SE } & \multirow[t]{2}{*}{ Weight } & \multirow[t]{2}{*}{$\begin{array}{l}\text { Spectacle compliance } \\
\text { IV, Random, } 95 \% \mathrm{Cl}\end{array}$} & \multicolumn{3}{|c|}{$\begin{array}{l}\text { Spectacle compliance } \\
\text { IV, Random, } 95 \% \mathrm{Cl}\end{array}$} & \\
\hline & Vear & & & & & & & \\
\hline $\begin{array}{l}\text { Zhou, } 2017 \\
\text { Subtotal }(95 \% \mathrm{CI})\end{array}$ & -0.041 & 0.01 & $\begin{array}{l}33.5 \% \\
33.5 \%\end{array}$ & $\begin{array}{l}0.96[0.94,0.98] \\
0.96[0.94,0.98]\end{array}$ & & & 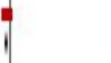 & \\
\hline \multicolumn{8}{|c|}{$\begin{array}{l}\text { Heterogeneity: Not applicable } \\
\text { Test for overall effect: } Z=4.10(P<0.0001)\end{array}$} & \\
\hline \multicolumn{8}{|c|}{ 2.4.2 Wearing or having it at school } & \\
\hline $\begin{array}{l}\text { Kaey, } 2010 \\
\text { Subtotal }(95 \% \mathrm{Cl})\end{array}$ & -0.71 & 0.05 & $\begin{array}{l}33.3 \% \\
33.3 \%\end{array}$ & $\begin{array}{l}0.49[0.45,0.54] \\
0.49[0.45,0.54]\end{array}$ & & $\ddot{1}$ & & \\
\hline \multicolumn{9}{|c|}{ Heterogeneity: Not applicable } \\
\hline \multicolumn{9}{|l|}{ 2.4.3 Observed wear } \\
\hline $\begin{array}{l}\text { Rewri, } 2013 \\
\text { Subtotal }(95 \% \mathrm{Cl})\end{array}$ & -1.119 & 0.065 & $\begin{array}{l}33.1 \% \\
33.1 \%\end{array}$ & $\begin{array}{l}0.33[0.29,0.37] \\
0.33[0.29,0.37]\end{array}$ & & 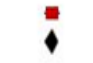 & & \\
\hline \multicolumn{9}{|c|}{$\begin{array}{l}\text { Heterogeneity: Not applicable } \\
\text { Test for overall effect: } Z=17.22 \text { ( } P<0.00001)\end{array}$} \\
\hline Total $(95 \% \mathrm{Cl})$ & & & $100.0 \%$ & $0.54[0.27,1.05]$ & & & & \\
\hline \multicolumn{5}{|c|}{$\begin{array}{l}\text { Heterogeneity: } \text { Ta }^{2}=0.35 ; C h i^{2}=428.38, d f=2(P<0.00001) ; I^{2}=100 \% \\
\text { Test for overall effect: } Z=1.81(P=0.07)\end{array}$} & 0.05 & 0.2 & $1 \quad 5$ & $\begin{array}{c}10 \\
20 \\
\text { pliance }\end{array}$ \\
\hline
\end{tabular}

Figure 4 Forest plot showing spectacle compliance at $<3$ month.

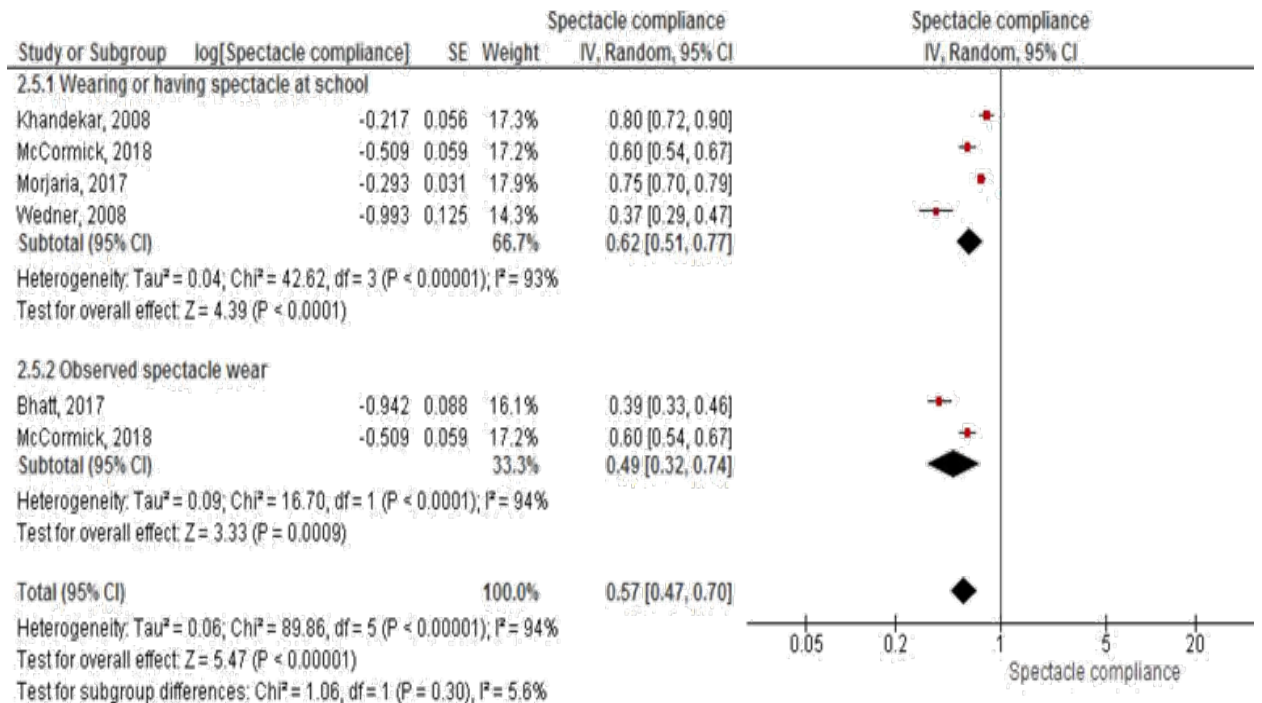

Figure 5 Forest plot showing spectacle compliance at 3 months.

\begin{tabular}{|c|c|c|c|c|c|c|c|}
\hline Study or Subgroup & log[Spectacle compliance] & SE & \multirow[t]{2}{*}{ Weight ${ }^{\text {S }}$} & \multicolumn{2}{|l|}{$\begin{array}{l}\text { Spectacle compliance } \\
\text { IV, Random, } 95 \% \mathrm{Cl}\end{array}$} & \multicolumn{2}{|c|}{$\begin{array}{l}\text { Spectacle compliance } \\
\text { IV, Random, } 95 \% \mathrm{Cl}\end{array}$} \\
\hline \multicolumn{7}{|c|}{ 2.6.1 Self-reported spectacle wear } & \\
\hline $\begin{array}{l}\text { Ma, } 2018 \\
\text { Subtotal }(95 \% \mathrm{Cl})\end{array}$ & -0.439 & 0.024 & $\begin{array}{l}12.7 \% \\
12.7 \%\end{array}$ & $\begin{array}{l}0.64[0.62,0.68] \\
0.64[0.62,0.68]\end{array}$ & & i & \\
\hline \multicolumn{8}{|c|}{ Heterogeneity: Not applicable } \\
\hline \multicolumn{8}{|c|}{ 2.6.2 Wearing or having spectacle at school } \\
\hline Congdon 2011 & -1.374 & 0.03 & $12.7 \%$ & $0.25[0.24,0.27]$ & & - & \\
\hline Congdon,2008 & -0.805 & 0.051 & $12.6 \%$ & $0.45[0.40,0.49]$ & & * & \\
\hline Wang, 2017 & -1.442 & 0.061 & $12.6 \%$ & $0.24[0.21,0.27]$ & & - & \\
\hline Wedner, 2008 & -0.853 & 0.112 & $12.1 \%$ & $0.43[0.34,0.53]$ & & $\rightarrow$ & \\
\hline $\begin{array}{l}\text { Yi, } 2015 \\
\text { Subtotal }(95 \% \mathrm{Cl})\end{array}$ & -0.611 & 0.035 & $\begin{array}{r}0.0 \% \\
50.0 \%\end{array}$ & $\begin{array}{l}0.54[0.51,0.58] \\
0.32[0.23,0.45]\end{array}$ & & & \\
\hline \multicolumn{8}{|c|}{$\begin{array}{l}\text { Heterogeneity: } \mathrm{Tau}^{2}=0.11 ; \mathrm{Chi}^{2}=115.59, \mathrm{df}=3(P<0.00001) ; I^{2}=97 \% \\
\text { Test for overall effect: } Z=6.72(P<0.00001)\end{array}$} \\
\hline \multicolumn{8}{|c|}{ 2.6.3 Observed spectacle wear } \\
\hline Aldebasi,2013 & -1.105 & 0.057 & $12.6 \%$ & $0.33[0.30,0.37]$ & & $*$ & \\
\hline Shukla, 2018 & -1.02 & 0.106 & $12.2 \%$ & $0.36[0.29,0.44]$ & & $\rightarrow$ & \\
\hline $\begin{array}{l}\text { Sumana, } 2015 \\
\text { Subtotal }(95 \% \mathrm{CI})\end{array}$ & -0.958 & 0.071 & $\begin{array}{l}12.5 \% \\
37.3 \%\end{array}$ & $\begin{array}{l}0.38[0.33,0.44] \\
0.35[0.32,0.39]\end{array}$ & & $\vec{\nabla}$ & \\
\hline \multicolumn{8}{|c|}{$\begin{array}{l}\text { Heterogeneity: } \text { Tau }^{2}=0.00 ; C h \mathrm{I}^{2}=2.66, \mathrm{df}=2(P=0.26) ; \mathrm{I}^{2}=25 \% \\
\text { Test for overall effect: } Z=21.20(P<0.00001)\end{array}$} \\
\hline Total $(95 \% \mathrm{Cl})$ & & & $100.0 \%$ & $0.37[0.26,0.52]$ & & & \\
\hline $\begin{array}{l}\text { Heterogeneity: Tauz } \\
\text { Test for overall effec }\end{array}$ & $\begin{array}{l}0.23 ; \mathrm{Chi}^{2}=714.43, \mathrm{df}=7(\mathrm{P} \\
\mathrm{Z}=5.83(\mathrm{P}<0.00001)\end{array}$ & $<0.000$ & $01) ; 1^{2}=99$ & & 0.05 & 0.2 & $\begin{array}{cc}1 & 1 \\
\text { Spectacle compliance }\end{array}$ \\
\hline
\end{tabular}

Figure 6 Forest plot showing spectacle compliance at 6 months.

Citation: Opare A, Abdullahi LH, Minnies D, et al. School vision screening programmes in reducing uncorrected refractive error among children in Low and Middle-Income countries-LMIC (systematic review). Adv Ophthalmol Vis Syst. 2020;10(4):91-105. DOI: I0.15406/aovs.2020.10.00392 


\section{More than six months after a school vision screening}

Seven studies assessed spectacle compliance at more than 6 month after school vision screening. The results of these studies indicate that $32 \%$ of children provided with spectacles as part of school vision screening may be compliant with it wear at more than six months follow-up (95\% CI: 14\%; 72\%, I2=100\%,) (Figure 7). We judged this to be low certainty evidence, downgrading 2 levels for high risk of bias and in- consistency. The level of spectacle wear compliance for each of the follow-up period differed based on the definition of 'compliance' used in the various studies (high heterogeneity). Studies that defined compliance as either 'self-reported wear' or 'teacher reported wear' reported the highest level of compliance while studies that defined compliance as 'observed wear' re-ported the lowest level of compliance as shown in Figure 8. Figure 9 shows a summary of compliance.

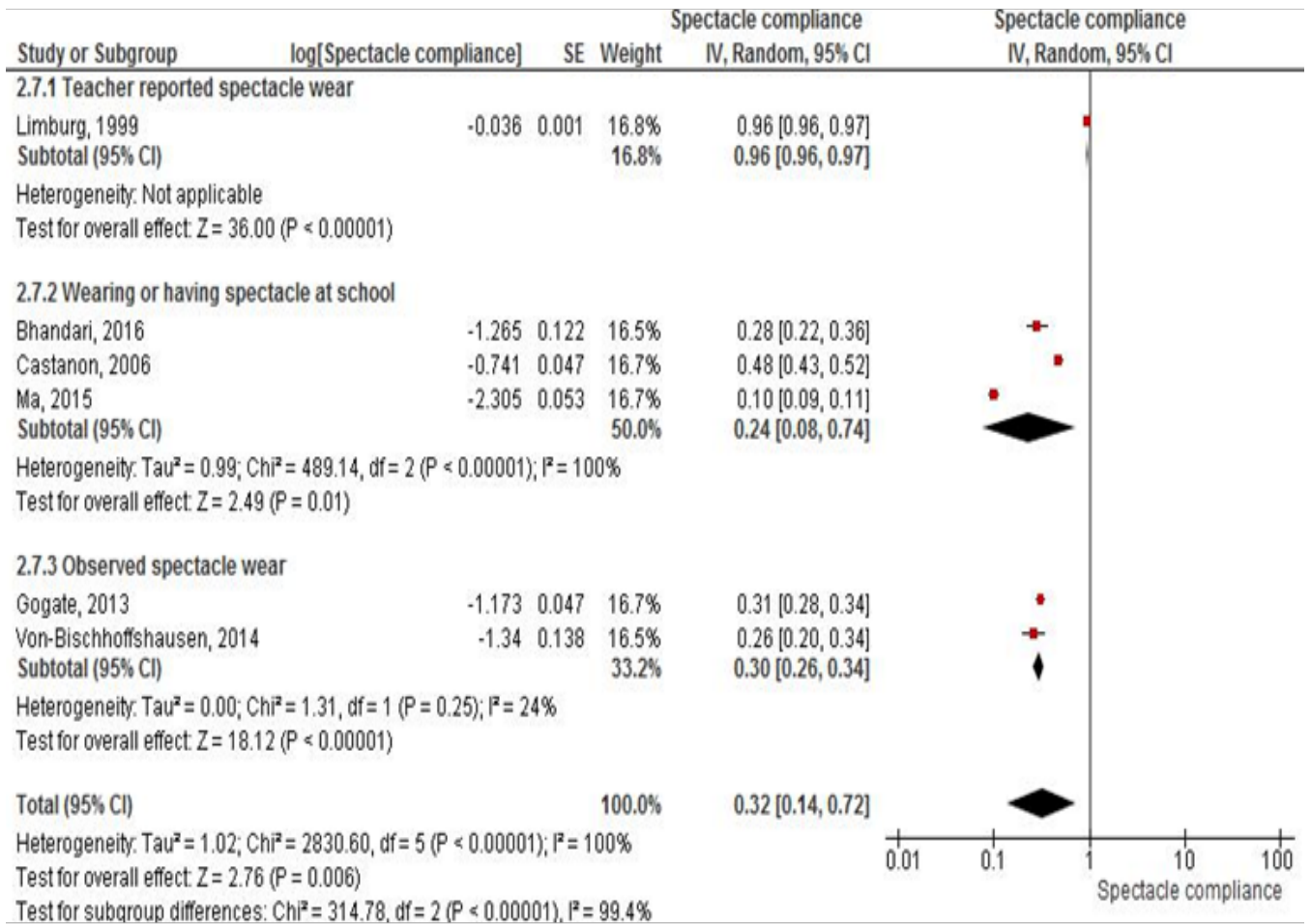

Figure 7 Forest plot showing spectacle compliance at $>6$ month.

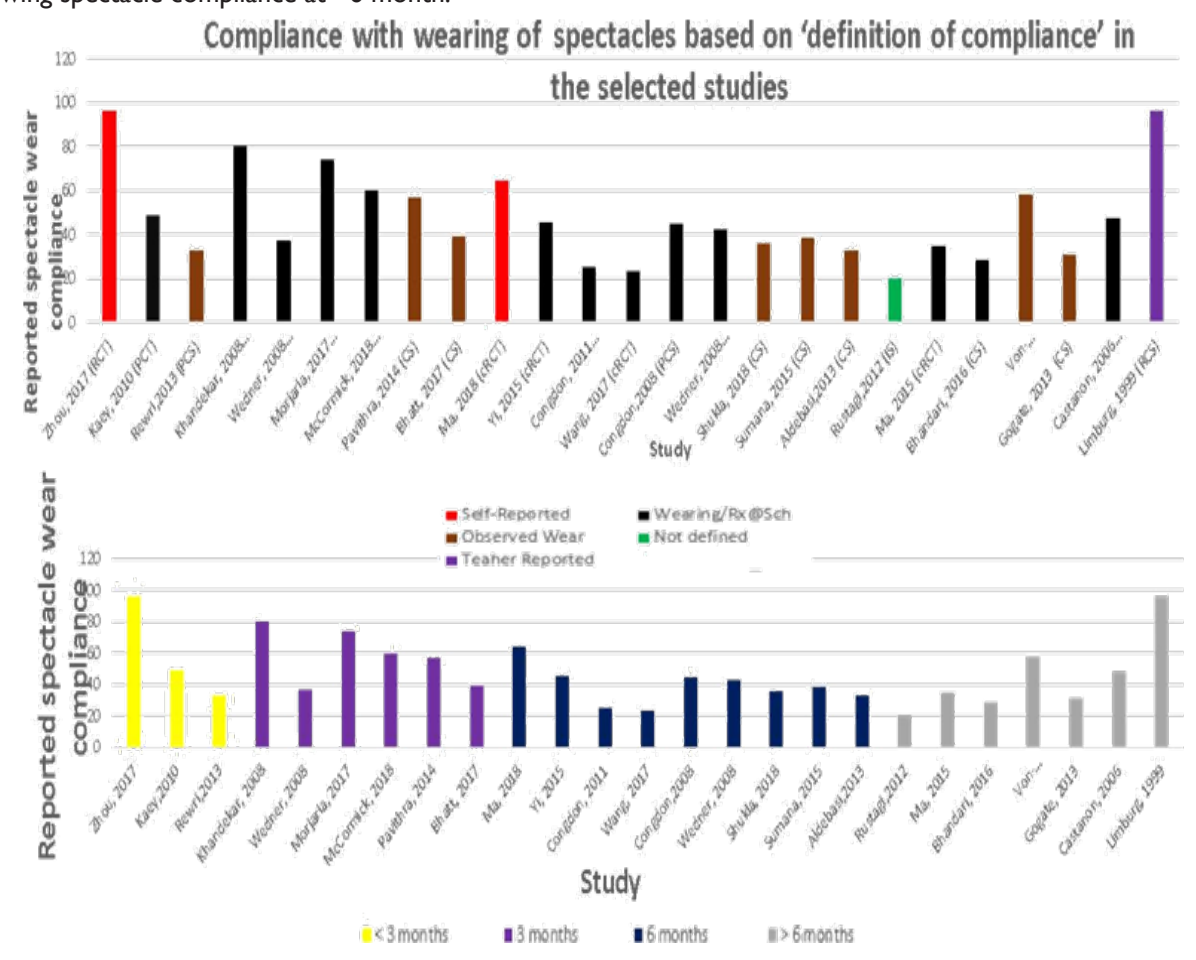

Figure 8 Compliance with wearing of spectacles based on definition of 'compliance' used in the various studies. 


\section{Pooled spectacle wear compliance by follow-up period}

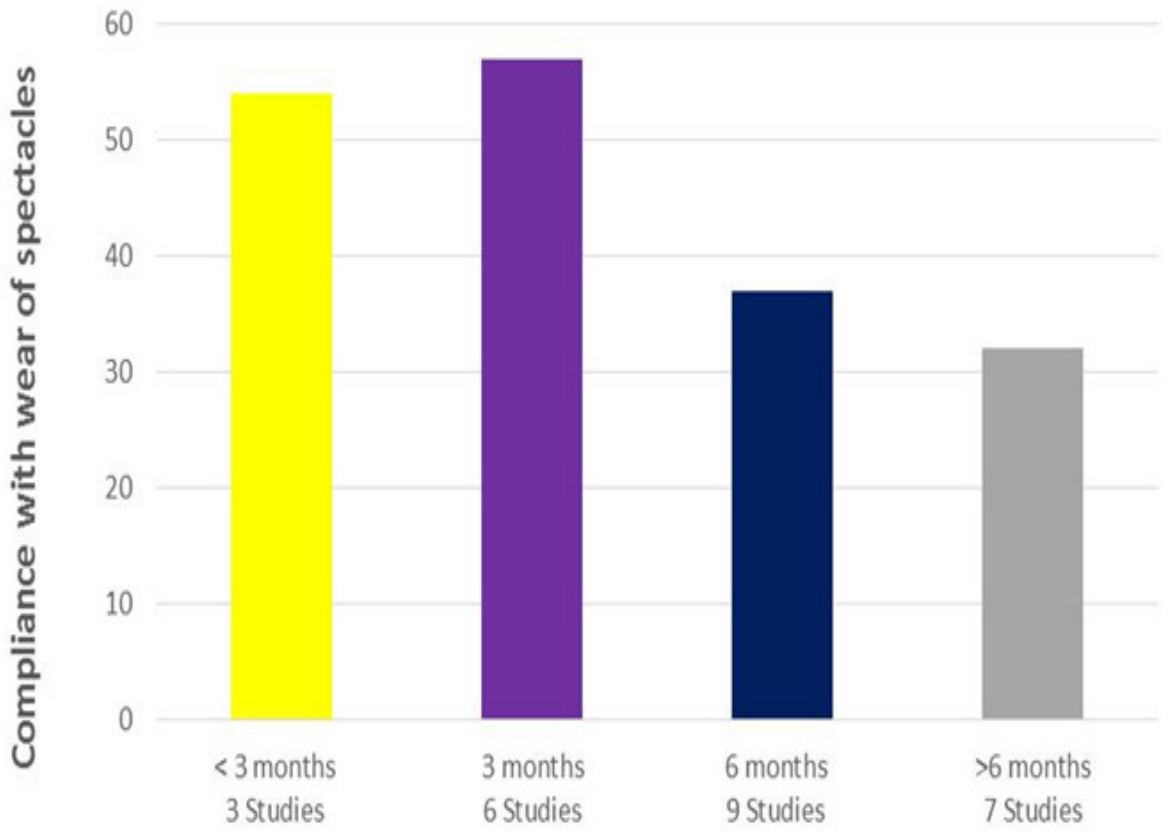

\section{Follow-up period}

Figure 9 Pooled spectacle wear compliance by follow-up period.

\section{Outcome: cost-effectiveness of school vision screening}

Five studies reported school vision screenings to be cost-effective (Moderate certainty evidence). One study estimated the overall cost of screening and provision of spectacle for each student to be $\$ 0.87$. This was reported to be nearly one- fourteenth of the Tanzania total health expenditure on health of $\$ 12$ per capita in 2004. This evidence was however judged to be of low certainty after downgrading two levels for indirectness since the cost estimate was specific to Tanzania and estimation was done about ten years ago. One study ${ }^{12}$ estimated the cost of buying high quality spectacles in bulk which is normally the case in most school vision screening programmes to be less than $\$ 5$ compared to the median price of approximately $\$ 60$ (almost half the monthly income for rural families in China) paid by each child who owned a pair of spectacles outside the school vision screening context. We judged this to be moderate certainty evidence, downgrading one level for indi-rectness since the cost estimate was specific to China. One study 22 compared the cost of screening per child using an "all class teacher model" versus a "selected class teacher model" in India and found school vision screening programmes involving all class teachers to be efficient and cost-effective (moderate certainty evidence). The cost of screening one child using the "all class teacher model" was estimated to be $\$ 1.91$ compared to the $\$ 4.83$ per child screened using the "selected teacher model" One study estimated the overall cost of screening one child based on the cost of the materials used in school vision screening (visual acuity cards, tape measure, etc). The cost of screening one child with no refractive error was estimated to be less than $\$ 0.03$ while the cost of screening and providing spectacles for a child with the refractive error was estimated to be $\$ 2.55$. We judged this to be low certainty evidence downgrading two levels for indirectness since the cost estimate was specific to India and cost estimation was done about 23 years ago.
The direct cost of screening one student with no ocular abnormality (excluding project management and traveling expenses) was estimated by one study to be approximately $\$ 0.5$. This cost, however, increased to $\$ 34.2$ per child for implementation of nationwide programmes targeting children with treatable mild, moderate and severe problems and $\$ 76.2$ for nationwide programmes targeting only children with moderate and severe conditions. The certainty of this evidence was judged by us to be low, downgraded 3 levels for imprecision based on the risk of bias assessment and indirectness as cost estimate is specific to Thai- land and estimation was done 9 years ago.

\section{Outcome: Impact of school vision screening on the academic performance of children}

Five studies; reported on the impact of school vision screening on the ac-ademic performance of children. All five studies reported that school vision screenings had a positive impact on the academic performance of children. Improvement in mathematics test score from $0.22(\mathrm{SD} ; 0.99)$ at baseline to $0.34(\mathrm{SD} ; 0.99)$, eight months after school vision screening (change of 0.13 , CI: 0,008-0.17) was reported by one study. ${ }^{12}$ The authors reported that despite the low level of compliance with spectacle wear observed in the study, screening, and provision of spectacles had a statistically significant impact on the academic performance of children. We judged this to be moderate certainty evidence; downgrading one level for indirectness. One study (15) compared the improvement in mathematics test score between children who received free spectacles and teacher incentive to improve spectacle compliance with and that of children who only received a prescription for spectacle and found an improvement in mathematics test score in the two groups, six months after school vision screening. The authors reported that children in schools that received the free spectacles and teacher incentive as part of school 
vision screening performed slightly better in the mathematics test, but this was not statistically significant $(\mathrm{P}=0.02)$. We graded this evidence to be of moderate certainty, downgrading one level for indirectness.

In one study (13), improvement in mathematics test score was compared between children in the "early referral to the hospital" and "late referral to hospital" group. The mean baseline mathematics test score was reported to be $0.09(\mathrm{SD} ; 1.1)$ and $-0.05(\mathrm{SD} ; 1.0)$ in the "early referral to hospital" and "late referral to hospital" groups respectively. The mean mathemat-ics test score increased at 6 months follow up to $0.14(\mathrm{SD} ; 1.01)$ and $-0.16(0.97)$ in the "early referral to the hospital" and "late referral to hospital" group respectively with the adjusted effect on mathematics test score comparing the two groups reported being $0.25 \mathrm{SD}(95 \% \mathrm{CI}, 0.01 ; 0.48,1$-sided $\mathrm{P}=0.04)$. The authors reported that this point estimate of the effect of the intervention was equivalent to half a semester additional learning. We graded this to be moderate certainty evidence, downgrading one level for indirectness. One study (64) reported that among children who were compliant to wearing spectacles prescribed as part of school vision screening, $42(87.5 \%)$ had an improvement in academic performance which was confirmed in $36(85.7 \%)$ of the students by teachers. We judged this to moderate certainty evidence after downgrading one level for indirectness. Another study (32) also reported a higher average academic score among children who were compliant with spectacle wear compared to those who were non-compliant, but this evi-dence was judged to be of low certainty, downgrading two levels for imprecision (a small number of events) and indirectness.

\section{Outcome:The adverse effect of school vision screening}

The adverse effect of school vision screening was reported by three studies. One study reported a reduction in LogMar visual acuity from $0.59(\mathrm{SD} ; 0.22)$ at baseline to $0.71(\mathrm{SD} 0.21)$ at six-month followup with a change of $-0.12(95 \%$ CI $0.14,0.10)$. This evidence was judged to be of moderate certainty after downgrading one level for indirectness. One study found spectacles provided as part of school vision screening to be associated with $27.2 \%$ report of headache, $34.6 \%$ report of dizziness, $6.18 \%$ report of disorientation, $9.90 \%$ of nausea and $48.76 \%$ of eye strain. This reported effect however reduced to $21.50 \%$ headache, $7.00 \%$ disorientation, $22.2 \%$ dizziness, $7.48 \%$ nausea and $48.55 \%$ eye strain at 1 -month follow-up. We judged this to be moderate certainty evidence. Another study also reported the presence of symptoms of headache and dizziness among children who received spectacles at the start of the school vision screening which reduced at a one-month follow-up

\section{Discussions}

School vision screening programmes for refractive error are mainly aimed at reducing the number of children with uncorrected refractive error. Effectiveness of these programmes depends on correctly identifying children with uncorrected refractive errors. In addition, it also depends on ensuring that children identified with the condition are given the appropriate spectacle or contact lens correction at reasonable costs; and that these spectacles or contact lenses are worn on regular basis (compliance). The purpose of this review was to assess the effectiveness of school vision screening pro-grammes in reducing uncorrected refractive error among children in LMIC. Additionally, it sought to evaluate the level of compliance with wearing of spectacles provided as part of school vision screening programmes. We further sought to assess the cost-effectiveness of school vision screening programmes, the effect of school vision screenings on the academic performance of children and adverse effect of school vision screenings in the LMICs context. Our review found that introducing vision screening programmes in schools may be an effective way of reducing the number of children with uncorrected refractive error. Because pro-vision of free spectacles to children identified with uncorrected refractive error has become central to most school vision screening programmes in recent times, this finding is not unexpected. The reduction in the proportion of children with uncorrected refractive error after the introduction of school vision screening programmes was found to be higher at two months follow-up (80.5\%). This however reduced to $24 \%$ and $20 \%$ at six- and eight-months post school vision screenings respectively. Since provision of spectacles to correct refractive error among children has become central to most school vision screening programmes in low- and middle-income countries, it is possible that the lower reduction in uncorrected refractive error at longer follow-ups (six and eight months) was due to most children losing their spectacles within that period. Compliance with wearing of spectacles was also found to be lower at longer follow-up period (six and more than six months post-school vision screening). This implies that effective monitoring of school vision screening programmes after its introduction may be key to its success in the long term.

Compliance with the wearing of spectacles provided as part of school vision screening, similar to a Cochrane review (8) was found to vary among the various studies and ranged between $32 \%$ to $96 \%$. The possible reason for this could be the different definition of 'compliance' used in these studies. Spectacle compliance was defined as 'wearing or having it at school', 'self-reported wear' or 'observed wear' by the various studies included in this systematic review. Considering the fact that the different definition used as indication of spectacle compliance by the various studies could have had an effect on the pooled spectacle compliance found in this review, we conducted a sub-group analysis based on the definition and the result is presented in Figure 4-7. This should be taken into consideration when interpreting the result of this review. The pooled spectacle wear compliance found in this systematic review was slightly lower than was reported in a Cochrane review. This outcome was however assessed from ten studies compared to only two studies from the Cochrane review and the use of 'observed wear' as indication for spectacle compliance in eight of the studies included in our review compared to "self- reported wear' in the two studies included in the Cochrane review could have led to an over- estimation of the pooled level of spectacle compliance found in the Cochrane review. This review also found school vision screening together with the provision of spectacles be relatively cost-effective. This result agrees with a recent Cochrane review ${ }^{8}$ which found vision screening and provision of spectacles to be a relatively cost-saving way of correcting children with uncorrected refractive error in the LMIC settings. In terms of the impact of school vision screening programmes on the academic performance of children, our review found a positive association between the introduction of school vision screening programmes and improvement in the academic performance of children. This result also agrees with the findings from both a Cochrane review ${ }^{8}$ and WHO review.

While symptoms such as dizziness, disorientation, nausea, and eye strain were found to be associated with the initial use of spectacles provided as part of school vision screening programmes, our review found that these symptoms improved significantly at follow-up indicating that school vision screening is relatively safe in identifying and treating children with un-corrected refractive error considerable effort was made to ensure the overall completeness of this systematic review by including all studies conducted in LMICs that assessed our review objectives. Our study found school vision screening programmes to be a relative cost-effectiveness method of reducing 
the proportion of children with uncorrected refractive error. Despite a comprehensive search strategy to ensure all studies conducted in LMICs that met our eligibility criteria were included, most of the papers included in this review came from Asia and the applicability of this evidence to other LMICs where none of the included studies came from may be limited. This is especially the case as vision screening programmes have been shown to vary across different settings. This means that the result of this review should be applied with caution when assessing the effectiveness of school vision screening in other countries or set- tings especially those outside the LMICs.

Another important limitation of this review is that the pooled spectacle compliance found in this review was obtained from studies that used different definitions as an indication of spectacle compliance. Studies that defined spectacle compliance based on 'self-reported wear' reported a higher level of compliance which may have overestimated the overall effect and studies that defined spectacle compliance based on 'observed wear' reported lower spectacle compliance which may have underestimated the pooled spectacle compliance. This should be taken into consideration in interpreting the result of this review. This review also included only papers published in the English language. This means that papers published in other languages were missed and the effect of excluding these papers on the over- all effects reported in this review is not clear.

\section{Conclusion}

Results of this review shows that school vision screening programmes may provide a safe and cost-effective way of reducing the proportion of children with uncorrected refractive error, with positive impact on academic performance of children. Most of the studies included in this review were however conducted in Asia and the applicability of the findings to other parts of the world may be limited. Studies, particularly randomized control trials (RCTs), that assess the effectiveness of school vision screening programmes in regions like Africa where few studies have been conducted are highly recommended. Additionally, considerable variation was found in the definition of spectacle compliance by the various studies which likely had an effect on the pooled spectacle compliance reported in this review. Establishing a common global definition for spectacle compliance to be used in subsequent studies may be an effective way to ensure accurate estimation of overall spectacle compliance in subsequent reviews.

\section{Acknowledgments}

We will like to acknowledge the authors of the various studies cited and/or included in this systematic review.

\section{Supporting information}

\section{Author summary}

\section{Why was this study done?}

The prevalence of uncorrected refractive error among schoolage children is on the rise with detrimental effect on academic performance. School vision screening programmes appear to be an effective way of identifying children with uncorrected refractive errors so early intervention can be made. Despite the increasing popularity of school vision screening programmes in recent times, there is a lot of debate on its effectiveness in reducing uncorrected refractive errors among children in low and middle-income countries.

\section{What did the researchers do and find?}

We undertook a systematic review and meta-analysis of 30 (Randomized control trials, cross-sectional studies, case-control studies, and cohort studies) studies that assessed school vision screening programmes in low and middle-income countries. The reduction in the proportion of children with uncorrected refractive error after the introduction of school vision screening programs was found to be higher at two months follow-up $(80.5 \%)$. This however reduced to $24 \%$ and $20 \%$ at six and eight months post-school vision screenings respectively. School vision screening programmes were safe, cost-effective and had positive impact on the academic performance of children.

\section{What do these findings mean?}

Since the provision of spectacles to correct refractive error among children has become central to most school vision screening programs in low and middle-income countries, it is possible that the lower reduction in uncorrected refractive error at longer follow-ups (six and eight months) was due to most children losing their spectacles within that period. This implies that effective monitoring of school vision screening programs after its introduction may be key to its success in the long term.

\section{Funding}

None.

\section{Conflicts of interest}

Author declares that there is no conflict of interest.

\section{References}

1. Naidoo KS, Leasher J, Bourne RR, et al. Global vision impair-ment and blindness due to uncorrected refractive error, 1990-2010. Optometry and vision science: official publication of the American Academy of Optometry. 2016; 93(3):227-234.

2. Bourne RRA, Flaxman SR, Braithwaite T, et al. Magnitude, tem- poral trends, and projections of the global prevalence of blindness and distance and near vision impairment: a systematic review and meta-analysis. Lancet Global health. 2017;5(9):e888-e97.

3. Waddell K. Spherical refraction for general eye workers. Journal of Community Eye Health. 2000;13(33):6-8.

4. Powell C, Hatt SR. Vision screening for amblyopia in childhood. Cochrane Database of Sys-tematic Reviews. 2009(3).

5. Powell C, Wedner S, Hatt SR. Vision screening for correctable visual acuity deficits in school- age children and adolescents. Cochrane Database of Systematic Reviews. 2004(4).

6. Paudel P, Kovai V, Naduvilath T, et al. Validity of teacher-based vi-sion screening and factors associated with the accuracy of vision screening in vietnamese chil-dren. Ophthalmic Epidemiol. 2016;23(1):63-68.

7. Wedner S, Dineen B. Refractive errors. Tropical doctor. 2003;33(4):207209.

8. Evans JR, Morjaria P, Powell C. Vision screening for correctable visual acuity deficits in school-age children and adolescents. Cochrane Database Systematic Rev. 2018;2:Cd005023.

9. Higgins JPT, Altman DG, Gøtzsche PC, et al. The cochrane collaboration's tool for assessing the risk of bias in randomized trials. $B M J$. 2011;343:d5928. 
10. Wedner S, Masanja H, Bowman R, et al. Two strategies for correct-ing refractive errors in school students in Tanzania: randomized comparison, with implications for screening programs. The British journal of ophthalmology. 2008;92(1):19-24.

11. Ma X, Congdon N, Yi H, et al. Safety of spectacles for chil-dren's vision: a cluster-randomized controlled trial. American journal of ophthalmology. 2015;160(5):897-904.

12. Ma X, Zhou Z, Yi H, et al. Effect of providing free glasses on chil-dren's educational outcomes in China: cluster randomized controlled trial. BMJ (Clinical research ed). 2014;349:g5740.

13. Ma Y, Congdon N, Shi Y, et al. Effect of a local vision care center on eyeglasses use and school performance in rural china: a cluster randomized clinical trial. JAMA Ophthalmol. 2018;136(7):731-737.

14. Wang X, Congdon N, Ma Y, et al. Cluster-randomized controlled trial of the effects of free glasses on purchase of children's glasses in China: the PRICE (Potentiating Rural Investment in Children's Eyecare) study. PloS one. 2017;12(11): $\mathrm{e} 0187808$.

15. Yi H, Zhang H, Ma X, et al. Impact of a teacher incentive on children's use of eyeglasses: a cluster- randomized controlled trial. Investigative ophthalmology and visual science Conference. 2015.

16. Congdon N, Li L, Zhang M, et al. Randomized, controlled trial of an educational intervention to promote spectacle use in rural China: the see well to learn well study. Ophthalmology. 2011;118(12):2343-2350.

17. Morjaria P, Bastawrous A, Murthy GVS, et al. Effectiveness of a novel mobile health education intervention (Peek) on spectacle wear among children in India: study protocol for a randomized controlled trial. Trials. 2017;18(1):168.

18. Zeng Y, Keay L, He M, et al. A randomized, clinical trial evaluating ready-made and custom spectacles delivered via a school-based screening program in China. Oph-thalmology. 2009;116(10):1839-1845.

19. Zhou Z, Chen T, Jin L, et al. Self-refraction, ready-made glasses and quality of life among rural myopic Chinese children: a non- inferiority randomized trial. Acta oph-thalmologica. 2017;95(6):567-575.

20. Keay L, Zeng Y, Munoz B, He M, et al. Predictors of early acceptance of free spectacles provided to junior high school students in China. Archives of ophthalmology (Chicago, Ill: 1960). 2010;128(10):1328-1334.

21. Priya A, Veena K, Thulasiraj R, et al. Vision screening by teachers in southern Indian schools: testing a new "all class teacher" model. Ophthalmic Epidemiol. 2015;22(1):60-65.

22. Rustagi N, Uppal Y, Taneja DK. Screening for visual impairment: outcome among schoolchildren in a rural area of Delhi. Indian $J$ Ophthalmol. 2012;60(3):203-206.

23. Castanon Holguin AM, Congdon N, Patel N, Ratcliffe A, Esteso $\mathrm{P}$, Toledo Flores S, et al. Factors associated with spectacle-wear compliance in school-aged Mexican children. Invest Oph-thalmol Vis Sci. 2006;47(3):925-958.

24. Congdon NG, Patel N, Esteso P, et al. The association between refractive cutoffs for spectacle provision and visual improvement among schoolaged children in South Africa. Br J Ophthalmol. 2008;92(1):13-18.

25. Limburg H, Kansara HT, d'Souza S. Results of school eye screening of 5.4 million children in India--a five-year follow-up study. Acta ophthalmologica Scandinavica. 1999;77(3):310-314.

26. Rewri P, Kakkar M, Raghav D. Self-vision testing and intervention seeking behavior among school children: a pilot study. Ophthalmic Epidemiol. 2013;20(5):315-320.

27. Von-Bischhoffshausen FB, Munoz B, Riquelme A, et al. Spectaclewear compliance in school children in Concepcion Chile. Ophthalmic Epidemiol. 2014;21(6):362-369.
28. Aldebasi YH. A descriptive study on the compliance of spectaclewear in children of primary schools at Qassim Province, Saudi Arabia. International journal of health sciences. 2013;7(3):291-299.

29. Bhandari G, Sangita Pradhan, Manisha Shrestha, et al. Eye Glasses Compliance among Children Undergoing School Visual Acuity Screening in Nepal. Adv Ophthalmol Vis Syst. 2016;5(3):286-290.

30. Bhatt N, Rathi M, Dhull CS, et al. Spectacle compliance amongst school children of Rohtak, Haryana, India. IJCMPH. 2017;734-737.

31. Gogate P, Mukhopadhyaya D, Mahadik A, et al. Spectacle compliance amongst rural secondary school children in Pune district, India. Indian J Ophthalmol. 2013;61(1):8-12.

32. Khandekar R, Parast N, Arabi A. Evaluation of 'vision screening' program for three to six-year-old children in the Republic of Iran. Indian J Ophthalmol. 2009;57(6):437-442.

33. Limburg H, Vaidyanathan K, Dalal HP. Cost-effective screening of schoolchildren for refrac-tive errors. World health forum. 1995;16(2):173-178.

34. McCormick I, Morjaria P, Mactaggart I, et al. Spectacle Compliance and Its Determinants in a School Vision Screening Pilot in Botswana. Ophthalmic Epidemiol. 2019;26(2):109-116.

35. Pavithra MH, L \& Madhukumar, Suwarna. Factors associated with spectacle wear compliance among school children of 7-15 years in South India. International Journal of Medicine and Public Health. 2014.

36. Shukla P, Vashist P, Singh SS, et al. Assessing the inclusion of primary school children in vision screening for refractive error program of India. Indian J Ophthalmol. 2018;66(7):935-939.

37. Sumana M, Sreelatha CY, Sagar K, et al. Prevalence of refractive error and other ocular morbidities and follow-up study on compliance to spectacles use among school going children aged 9-16 years in the selected village of Hassan. Journal of Evolution of Medical and Dental Sciences-Jemds. 2015;4(96):16163-16166.

38. Tengtrisorn S, Sangsupawanitch P, Chansawang W. Cost-effectiveness analysis of a vision screening program in Thailand. $J$ Med Assoc Thai. 2009;92(8):1050-1056.

39. Rustagi N, Uppal Y, Taneja DK. Screening for visual impairment: outcome among schoolchildren in a rural area of Delhi. Indian J Ophthalmol. 2012;60(3):203-206.

40. Morjaria P, Bastawrous A, Murthy GVS, et al. Effectiveness of a novel mobile health education intervention (Peek) on spectacle wear among children in India: study protocol for a randomized controlled trial. Trials. 2017;18(1):168.

41. Narayanan A, Ramani KK. Effectiveness of interventions in improving compliance to spectacle wear and referral in school vision screening. Clin Exp Optom. 2018;101(6):752-757.

42. Ma X, Congdon N, Yi H, et al. Safety of Spectacles for Children's Vision: a Cluster-Randomized Controlled Trial. Am J Ophthalmol. 2015;160(5):897-904

43. Ma X, Zhou Z, Yi H, et al. Effect of providing free glasses on children's educational outcomes in China: cluster randomized controlled trial. BMJ. 2014;349:g5740.

44. Ma Y, Congdon N, Shi Y, et al. Effect of a Local Vision Care Center on Eyeglasses Use and School Performance in Rural China: A Cluster Randomized Clinical Trial. JAMA Ophthalmol. 2018;136(7):731-737.

45. Wang X, Congdon N, Ma Y, et al. Cluster-randomized controlled trial of the effects of free glasses on purchase of children's glasses in China: The PRICE (Potentiating Rural Investment in Children's Eyecare) study. PloS one. 2017;12(11): $\mathrm{e} 0187808$. 
46. Yi H, Zhang $\mathrm{H}$, Ma X, et al. Impact of a teacher incentive on children's use of eyeglasses: a cluster- randomized controlled trial. Investigative ophthalmology and visual science. 2015.

47. Congdon N, Li L, Zhang M, et al. Randomized, controlled trial of an educational intervention to promote spectacle use in rural China: the see well to learn well study. Ophthalmology. 2011;118(12):2343-2350.

48. Zeng Y, Keay L, He M, et al. A randomized, clinical trial evaluating ready-made and custom spectacles delivered via a school-based screening program in China. Ophthalmology. 2009;116(10):1839-1845.

49. Zhou Z, Chen T, Jin L, et al. Self-refraction, ready-made glasses and quality of life among rural myopic Chinese children: a non- inferiority randomized trial. Acta ophthalmologica. 2017;95(6):567-575.
50. Keay L, Zeng Y, Munoz B, et al. Predictors of early acceptance of free spectacles provided to junior high school students in China. Arch Ophthalmol. 2010;128(10):1328-1334.

51. Von-Bischhoffshausen FB, Munoz B, Riquelme A, et al. Spectaclewear compliance in school children in Concepcion Chile. Ophthalmic Epidemiol. 2014;21(6):362-369.

52. Wedner S, Masanja H, Bowman R, et al. Two strategies for correcting refractive errors in school students in Tanzania: randomized comparison, with implications for screen-ing programs. $\mathrm{Br} J$ Ophthalmol. 2008;92(1):19-24.

53. Tengtrisorn S, Sangsupawanitch P, Chansawang W. Cost-effectiveness analysis of a vision screening program for primary school children in Thailand. J Med Assoc Thai. 2009;92(8):1050-1056. 